\title{
Firm Age and the Evolution of Borrowing Costs: Evidence from Japanese Small Firms
}

\author{
Koji Sakai* $\quad$ Iichiro Uesugi ${ }^{\dagger} \quad$ Tsutomu Watanabe ${ }^{\ddagger}$
}

First Draft: September 6, 2005

This Version: February 13, 2008

\begin{abstract}
This paper investigates how a firm's borrowing cost evolves as it ages. Using a new data set of more than 200,000 bank-dependent small firms for 1997-2002, we find the following. First, the distribution of borrowing costs tends to become less skewed to the right over time, which can be partially attributed to "selection" (i.e., exits of defaulting firms reduce the total borrowing costs), but is mainly explained by "adaptation" (i.e., surviving firms' borrowing costs decline as they age). Second, the selection process is natural in that firms with lower quality are separated, charged higher borrowing costs, and eventually forced to exit, which contrasts with the results of previous studies on Japan's credit misallocations, such as Peek and Rosengren (2005). Third, in the adaptation process, we find an age dependence of firms' borrowing costs even if we control for firm size.
\end{abstract}

JEL Classification Numbers: D82; D83; E43; G21; G30; L25

Keywords: firm age; borrowing cost; selection; credit allocation; reputation

\footnotetext{
${ }^{*}$ Graduate School of Economics, Hitotsubashi University, ed042002@srv.cc.hit-u.ac.jp

${ }^{\dagger}$ Institute of Economic Research, Hitotsubashi University, iuesugi@ier.hit-u.ac.jp

$\ddagger$ Institute of Economic Research, Hitotsubashi University, tsutomu.w@srv.cc.hit-u.ac.jp
} 


\section{Introduction}

What happens to a firm as it ages? This question has been addressed by a number of studies that empirically investigate the relationship between a firm's age and real activity variables, including the firm's growth, the volatility of its growth, and employment. Evans (1987b), for example, shows that the growth rate of U.S. small firms and the volatility of growth are both negatively correlated with firm age, while Cabral and Mata (2003), examining Portuguese manufacturing firms, find that the firm size distribution moves towards the right hand side as firms age. Meanwhile, Davis, Haltiwanger, and Schuh (1996), concentrating on U.S. manufacturing firms, report that the rates of job creation and destruction decrease with firm age. ${ }^{1}$ The purpose of this paper is to search for such "age dependence" in firms' financial activities rather than in their real activities. Specifically, we look for it in one of the most important financial variables for firms: their borrowing cost. Based on a unique panel data set of more than 200,000 small Japanese firms covering the period from 1997 to 2002, we provide a careful analysis of the relationship between firm age and borrowing cost.

Our study is closely related to that by Diamond (1989), which yielded an important prediction about the channel through which the borrowing cost distribution evolves with age. Specifically, Diamond (1989) investigated entrepreneurs' dynamic decision making in an environment in which borrowing costs crucially depend on a borrower's repayment record: a firm's borrowing costs decline over time as long as the firm maintains a good track record, while a single default leads to a large increase in the interest rate charged. Under these circumstances, borrowers with a long good track record tend to choose safe projects as they do not want to jeopardize this valuable asset, which further reduces their borrowing costs. One of the objectives of this paper is to examine whether such a negative correlation between age and borrowing costs among surviving firms can be found in our data set. ${ }^{2}$

\footnotetext{
${ }^{1}$ Other studies on this topic include those by Dunne, Roberts, and Samuelson (1989), who report that manufacturing plants that have been in business longer are less likely to close, and by Brown and Medoff (2003), who find a U-shaped relationship between firm age and wages.

${ }^{2}$ Studies other than Diamond's (1989) that draw a similar conclusion regarding the relationship between age and borrowing costs include Cooley and Quadrini (2001) and Petersen and Rajan (1994).
} 
Diamond's model, however, says little about the "selection" channel, which theoretical studies on firm dynamics have focused on as a determinant of industry evolution. The reason that Diamond's model has little to say about the selection channel simply is that borrowers are assumed to be observationally equivalent: imperfect information does not allow lenders to distinguish among different types of borrowers, so that all borrowers are lumped together and charged the same interest rate. Given the absence of any difference between prospective defaulters and survivors in terms of borrowing costs, it is almost impossible to say anything about the role of "selection" in the evolution of the borrowing cost distribution. In this respect, we depart from Diamond's setting and assume that there are two different channels through which the borrowing cost distribution evolves with firm age: "selection" and "adaptation." Selection affects the evolution of the borrowing cost distribution because prospective defaulters and survivors are different in terms of the interest rates they are charged. If it is true that nonviable firms that are later forced to exit from the market through selection pay higher interest rates than those that survive, we should observe that the average borrowing cost declines over time. On the other hand, adaptation affects the evolution of the borrowing cost distribution because survivors change their behavior as they age. Diamond's "reputation story," that is, the idea that the interest rate firms are charged reflects their credit history, is one possible explanation why survivors change their behavior with age. ${ }^{3}$

The interest of this paper is threefold. First, we are interested in the relative importance of selection and adaptation in the evolution of borrowing cost. In this respect, Cabral and Mata (2003) arrive at the interesting finding that selection plays a less important role in the evolution of firm size distribution than is assumed in the theoretical literature. This result is echoed by Okazaki's (2004) empirical finding that the role of selection did not play the dominant role in the evolution of Japanese main bank relationships. Second, we are interested in whether the selection we find is natural or unnatural. A number of scholars

\footnotetext{
${ }^{3}$ Needless to say, the words "selection" and "adaptation" are borrowed from evolutionary biology. We think this analogy is very useful to highlight what our exercise is about. However, we do not wish to take the analogy further, as we recognize that there are non-trivial differences between industrial evolution and biological evolution.
} 
have argued that the prolonged stagnation of the Japanese economy can be explained by the fact that inefficient "zombie" firms were allowed to stay in the market because of the perverse incentives provided by struggling banks and that the presence of such zombie firms crowded out new entrants with profitable investment opportunities, leading to a deterioration in the efficiency of the economy (Cabarello, Hoshi, and Kashyap (2006); Peek (2004); Peek and Rosengren (2005); Nishimura, Nakajima, and Kiyota (2005)). ${ }^{4}$ We would like to examine if this unnatural selection story is supported by the data. The third interest concerns the mechanism of adaptation. As shown empirically by Evans (1987a) and Hall (1987), among others, firm size plays an important role in firm dynamics. Given the positive association between firm size and age, this implies that firm age could be correlated with borrowing costs by way of firm size. We would like to distinguish this indirect relationship from the direct relationship between age and borrowing costs implied by theory, including the reputation story by Diamond (1989).

The remainder of the paper is organized as follows. Section 2 explains our empirical approach, including our methodology to identify the age effect. Section 3 empirically examines the three issues, that is, selection versus adaptation (section 3.1), natural versus unnatural selection (section 3.2), and age versus firm size in the adaptation mechanism (section 3.3). Section 4 concludes the paper.

\section{Empirical Approach}

\subsection{Data}

The data for this study were obtained from the Credit Risk Database (CRD),${ }^{5}$ which covers about 60 percent of small corporations in Japan. ${ }^{6}$ One of the advantage of the CRD is that it contains information about default events, of which there are four types: payments delinquent by three months or more; de

\footnotetext{
${ }^{4}$ In a related context, Cabinet Office of Japan (2003) claimed that to revitalize the economy, it would be necessary to close six percent of all large, publicly traded firms in Japan.

${ }^{5}$ The CRD was established in 2001 at the initiative of the Small and Medium Enterprises Agency of Japan (SMEA) in order to provide financial institutions with detailed and reliable balance sheet information on small businesses, thereby enabling financial institutions to make an accurate estimate of a firm's default probability.

${ }^{6}$ There were about 1.6 million small and medium-size corporations in Japan as of 2001, of which the CRD covers 0.9 million.
} 
facto failure; failure; repayment of debts by a loan guarantee corporation. Default information allows us to identify defaulters and non-defaulters in each year.

Using the more than 5 million firm-years contained in the CRD, we construct a panel data set as follows. First, we choose 1997-2002 as the sample period, so that we have enough observations for each year. Second, we limit the sample to firms satisfying either of the following two conditions: (1) the firm survived from 1997 to 2002 and reported information to the CRD Association in each year; or (2) the firm defaulted between 1997 and 2002 and reported information to the CRD until the year of default. Put differently, a firm is not included in our panel data set if it does not report to the CRD Association in 1997, or if it disappears without a record of default between 1997 and 2002. It should be noted that firms established in and after 1998 are not included in our data set. Third, we remove outliers for each variable based on the following rule. As for interest rates, we first remove outliers in the lower tail by omitting observations with an interest rate that is exactly zero (0.91 percent of the total observations) and then remove the same percentage of observations in the upper tail. As for other variables (operating profits, total asset, and net worth), we remove the top and bottom 1 percent of all observations. After making the above adjustments, we finally obtain a panel data set whose structure is described in Table 1. The number of firms is about 240,000 in 1997 and declines by about 8,000 per year, ${ }^{7}$ finally reaching about 200,000 in 2002.

Below we explain the major variables employed in our analysis.

Borrowing Cost: The CRD does not provide the borrowing cost for each individual loan contract. To calculate the borrowing cost, we divide interest payments for a year by the average of total borrowing outstanding (including discounted notes receivable) at the end of the current and previous years.

Birth Year and Firm Age: We define the year when a firm is registered at the Legal Affairs Bureau as its birth (cohort) year. The difference between the current year and the cohort year is the age of the

\footnotetext{
${ }^{7}$ The default rates are two to four percent per year.
} 
firm. The number of firms that are very old or very young is quite limited, and thus we mainly focus on the samples with cohort years between 1950 and 1995 .

Operating Profit: This performance variable is used as a measure of firms' observable quality. We define operating profit as profits divided by the value of total assets outstanding. Note that the operating profit here is before the payment of interest.

Total Assets and Net Worth: As proxies for firm size, we employ the following two variables: the total assets outstanding, and net worth defined as the difference between total assets and total liabilities.

Table 2 presents summary statistics for these variables. The mean borrowing cost of firms is 2.83 percent in the overall sample, and there is a substantial difference in performance between surviving and defaulting firms. The performance of defaulting firms in terms of operating profit is markedly worse than that of surviving firms. Furthermore, the size of defaulters is smaller than that of survivors both in terms of total assets and net worth.

\section{$2.2 \quad$ Identification of Age Effects}

Let us denote the borrowing cost of firm $i$, which belongs to birth cohort group $\tau$, in year $t$ by $R_{i}(t, \tau)$ and assume that $R_{i}(t, \tau)$ is determined as a confluence of three effects: a year effect $\alpha(t)$, a cohort effect $\beta(\tau)$, and an age effect $\gamma(t-\tau)$. That is,

$$
R_{i}(t, \tau)=\alpha(t)+\beta(\tau)+\gamma(t-\tau)+\epsilon_{i}(t, \tau)
$$

where $\epsilon_{i}(t, \tau)$ represents an idiosyncratic error term. Since there is an exact linear relationship between these three effects, a serious identification problem emerges when we try to extract the age effect. To be more specific, any cross-sectional approach inherently contains the confound of age and cohort effects, while any longitudinal approach contains that of age and year effects. For example, Petersen and Rajan 
(1995) use cross-sectional data to obtain the age profile of firms in terms of their borrowing costs under the assumption of "stationarity of the survival process" (p.419); however, if the survival process is not stationary, we cannot ignore the cohort effect, thereby fail to identify the age effect from the confound of age and cohort effects. ${ }^{8}$

It is easy to see that cross-sectional data are insufficient to overcome the identification problem and that dynamic data are indispensable. Also, as argued by Cabral and Mata (2003), it is natural to think that researchers need to have a dynamic data set at their hands if they seriously want to investigate the evolution of variables in relationship to firm age, independently of whether such variables are real or financial ones. However, having dynamic data is not sufficient to overcome the identification problem. One way to circumvent the identification problem is to make a normalization assumption. Deaton (1997), for example, proposes a normalization that makes the year effects orthogonal to the time trend, so that the entire effect is attributed to age and cohort effects. However, it is often noted that estimated results obtained by the normalization are extremely unstable, particularly in the case of a limited time-series horizon.

As an alternative way to cope with the identification problem, we remove year effects by subtracting the weighted average of short- and long-term prime lending rates from $R_{i}(t, \tau)$, using the share of shortand long-term borrowings outstanding at the end of each year as weights. ${ }^{9}$

The weighted prime rate can be seen as the risk-free rate, which is basically determined by monetary policy. In this sense, subtracting this from $R_{i}(t, \tau)$ amounts to removing the year effect $\alpha(t)$ in the cost

\footnotetext{
${ }^{8}$ Recent studies in the area of consumer behavior have shown that birth cohort effects are not negligible in the evolution of various variables related to consumer decision making. Given that our sample consists of small firms with about twenty employees on average, birth cohort effects could, as in the case of consumer decision making, play a non-negligible role in the evolution of borrowing costs.

${ }^{9}$ The procedure is as follows. First, we calculate the stock-based long- and short-term prime rates. The stock-based long-term prime rate is defined as the average of long-term prime rates over the past sixty months, while the stock-based short-term prime rate is defined as the average of short-term prime rates over the past twelve months. Second, we calculate the weighted stock-based prime rate for individual firms, with the share of long- and short-term borrowings outstanding at the end of each year used as weights. Third, we regress $R_{i}(t, \tau)$ on this weighted stock-based prime rate and a firm-specific term. We use the estimated coefficient on the weighted stock-based prime rate, 0.5488 (standard error 0.0016 ), to calculate adjusted borrowing costs.
} 
of borrowing, so that

$$
R_{i}(t, \tau)=\beta(\tau)+\gamma(t-\tau)+\epsilon_{i}(t, \tau)
$$

Then, it is easy to see that

$$
R_{i}(t+1, \tau)-R_{i}(t, \tau)=[\gamma(t-\tau+1)-\gamma(t-\tau)]+\epsilon_{i}(t+1, \tau)-\epsilon_{i}(t, \tau)
$$

which indicates that we identify the first difference of the age effect, although we are still not able to identify the age effect itself. Since we are mainly interested in the slope of the age profile of firms in terms of borrowing costs, the first difference provides sufficient information for our purposes, ${ }^{10}$ and we will basically adopt this method in the subsequent sections. ${ }^{11}$

\section{Empirical Results}

\subsection{Selection versus Adaptation}

We begin our empirical analysis by looking at the age profile of firms in terms of their borrowing costs.

We first take the mean of firms' borrowing costs and then take its first-order time difference. That is, we calculate

$$
E_{i \in A(t+1, \tau)} R_{i}(t+1, \tau)-E_{i \in A(t, \tau)} R_{i}(t, \tau),
$$

where $A(t, \tau)$ represents the set of all firms operating in year $t$ and belonging to the birth year cohort $\tau$. We then regress this expression on age dummy $D(a)$, which is equal to one if $t-\tau=a$ and is zero otherwise. The coefficient on the age dummy $D(a)$ represents the estimate for the slope of the age profile, $\hat{\gamma}(a+1)-\hat{\gamma}(a)$, which is shown in Figure 1 together with the $95 \%$ confidence interval. For most ages, the

\footnotetext{
${ }^{10}$ As proposed by McKenzie (2002), one can identify second differences of the age effects, $[\gamma(t-\tau+1)-\gamma(t-\tau)]-$ $[\gamma(t-\tau)-\gamma(t-\tau-1)]$, even without any strong assumptions. However, since the second differences provide information only about the curvature of the age profile of firms in terms of their borrowing costs (and no information about its slope), his methodology does not suit our purpose here.

${ }^{11}$ When the prime rate cannot further decrease due to the lower bound incurred, for example, by a zero interest rate, the weighted prime rate may exaggerate the year effect. This is especially the case during the periods of $1999-2000$ and 2001-2006, when the Bank of Japan introduced the zero interest rate policy and the quantitative easing policy, respectively. To examine such a possibility, shorter subsets of data for four years (1997-2000, 1998-2001, and 1999-2002) are used to generate the slopes of age profiles as in Figure 2. We find that the age profile is downward sloping through all sub-samples.
} 
slope is significantly negative. Next, given $\gamma(0)=0$ as a normalization, we add $\widehat{\gamma}(1)-\widehat{\gamma}(0), \widehat{\gamma}(2)-\widehat{\gamma}(1)$, $\widehat{\gamma}(3)-\widehat{\gamma}(2), \ldots$ to obtain the age profile presented in Figure 2, which shows important features of the age profile of firms in terms of their borrowing costs. First, the age profile is significantly downward sloping: the difference between age 0 and age 50 is about 170 basis points. Second, it is convex: the slope becomes smaller with age until it reaches almost zero at age 50. It is important to note that the age profile shown in Figure 2 contains two components: changes due to selection and changes due to adaptation. To discern the relative importance of these two components, Figure 3 compares three kinds of borrowing cost distribution: the solid line labeled "1997" represents the distribution of all firms in 1997; the broken line labeled "1997S" represents the distribution in 1997 of those firms that survived until the end of our sample period, 2002; and the dashed line labeled "2002" represents the distribution in 2002 of those firms that survived until 2002.

If we compare the "1997" and "2002" distributions, we can see that the "2002" distribution is less skewed to the right, and therefore the mean of the "2002" distribution is clearly smaller, which is consistent with the downward-sloping age profile we saw in Figure 2. This raises the question where this shift in borrowing cost distribution comes from. If we compare the "1997" and "1997S" distributions, we see that "1997S" is slightly less skewed to the right, which implies that selection plays a role in the shift of the borrowing cost distribution. On the other hand, if we compare the "1997S" and "2002" distributions, we see that "2002" is again less skewed to the right, which implies that adaptation plays a role in the shift of the distribution. However, as can be clearly seen in Figure 3, the contribution of selection in the evolution of the distribution is much smaller than that of adaptation. Figure 4 repeats the same exercise for each cohort and shows that (1) adaptation plays a more important role for each cohort and (2) the relative importance of selection is smaller, particularly for younger cohorts. To examine the relative importance of the two sources of evolution in a more robust manner, Table 3 decomposes the total evolution of borrowing costs from year $t$ to $t+1$ into evolution due to selection and evolution due 
to adaptation. That is,

$$
\begin{array}{r}
E_{i \in A(t+1, \tau)} R_{i}(t+1, \tau)-E_{i \in A(t, \tau)} R_{i}(t, \tau) \\
=\theta(t, \tau)\left[E_{i \in S(t, \tau)} R_{i}(t, \tau)-E_{i \in D(t, \tau)} R_{i}(t, \tau)\right] \\
+E_{i \in A(t+1, \tau)} R_{i}(t+1, \tau)-E_{i \in S(t, \tau)} R_{i}(t, \tau)
\end{array}
$$

where $S(t, \tau)$ represents the set of firms which belong to cohort $\tau$ and survive from year $t$ to $t+1$, $D(t, \tau)$ is the set of firms which belong to cohort $\tau$ and default in year $t+1$, and $\theta(t, \tau)$ is the default rate for cohort $\tau$ in year $t .^{12}$ Note that the first term on the right-hand side of the equation represents the contribution of selection, while the second term represents the contribution of adaptation.

Table 3 presents the decomposition results for the whole sample as well as for six industries: construction, manufacturing, wholesale, retail, real estate, and services. The rows labeled "Total" represent the left-hand side of equation (2), and the rows labeled "Selection" and "Adaptation" represent the first and second terms, respectively, on the right-hand side of equation (2). First, if we look at the whole sample (the first three rows labeled "All"), we can see that the figures for "Total" are negative for all cohorts and that their absolute values are smaller for older generations. These findings are consistent with the downward sloping and convex shape of the age profile we saw in Figure 2. Second, the figures in the "Selection" and "Adaptation" rows (the second and third rows) are again negative for all cohorts, indicating that both selection and adaptation play a role in the evolution of borrowing costs. However, if we look at the figures more closely, we see that the contribution of adaptation tends to be larger than that of selection. For example, the average over cohorts (figures in the upper right-hand corner) shows that the contribution of selection is about 36 percent $(-0.013$ out of -0.036$)$ while that of adaptation is 64 percent (-0.023 out of -0.036). ${ }^{13}$ This confirms our casual observation from Figure 3 and is also consistent with empirical findings reported by Cabral and Mata (2003) for the evolution of size distribution of ${ }^{12}$ To obtain equation (2), we use the identity $E_{i \in S(t, \tau)} R_{i}(t, \tau)-E_{i \in A(t, \tau)} R_{i}(t, \tau) \equiv \theta(t, \tau)\left[E_{i \in S(t, \tau)} R_{i}(t, \tau)-\right.$ $\left.E_{i \in D(t, \tau)} R_{i}(t, \tau)\right]$.

${ }^{13}$ Note that this does not necessarily imply that selection and adaptation are independent. In fact, as shown in Figure 5 , there exits a positive correlation between the two, suggesting that selection and adaptation are not independent. This correlation could be interpreted as evidence that selection facilitates adaptation, in the sense that firms try very hard to change their attributes if they face severe selection pressure, but do not do so otherwise. 
Portuguese firms, and Okazaki (2004) for the evolution of Japanese main bank relationships. ${ }^{14}$ Third, if we look at the figures for each industry, we see that the above three regularities hold for each industry, except in the case of the real estate industry where borrowing costs tend to increase with age.

\subsection{Natural versus Unnatural Selection}

The concept of natural selection was first applied to economics by Alchian (1950), who argued that the economy is a system of selection where market forces eliminate firms that do not earn profits. This idea has been adopted by many researchers, including Jovanovic (1982), who modeled the selection mechanism as firms' learning process about their efficiency.

Whether the selection process works properly or not has been one of the most important empirical issues regarding the Japanese economy in the late 1990s. Sekine, Kobayashi, and Saita (2003) and Peek and Rosengren (2005) use firm-level data to investigate whether the selection process worked properly for large, publicly traded firms. Using various performance indicators, including productivity, profitability, and debt ratios, to distinguish bad firms from good ones, they found that troubled banks tended to increase (rather than decrease) loans to bad firms in order to avoid realizing losses on their own balance sheets. They interpret this as evidence against natural selection, and Peek and Rosengren (2005) dub this "unnatural selection." ${ }^{15}$ Nishimura, Nakajima, and Kiyota (2005), moreover, found that in some Japanese industries during the latter half of the 1990s, there was a tendency for firms with low productivity to remain in business while those with high productivity exited. Furthermore, Caballero, Hoshi, and Kashyap (2006) and Ahearne and Shinada (2005) argue that Japanese banks have kept unprofitable firms ("zombie firms") alive by extending loans at subsidized low interest rates, and that

\footnotetext{
${ }^{14}$ On the other hand, Baldwin and Rafiquzzaman (1995) report that selection plays a dominant role in the evolution of firm performance (in terms of size, productivity, wages, and profitability) of young Canadian firms that have just entered an industry. In a related context, Bergoeing et al. (2002) compare a country with a proper selection mechanism (Chile) to one without (Mexico), and show that a proper selection process facilitates economic growth.

${ }^{15}$ Note that, in Peek and Rosengren's (2005) study, selection, be it natural or unnatural, does not imply market exit: unnaturally selected firms (with a poor performance) tend to increase their debts but continue to be allowed to stay in business. Presumably, this reflects the fact that Peek and Rosengren's sample is limited to publicly traded firms, which seldomly default.
} 
these zombies crowd out firms with profitable projects, thereby distorting the allocation of resources.

One common feature of studies along these lines is that they concentrate on large firms. ${ }^{16}$ This is partly based on the belief that the misallocation of bank loans occurs only in the case of large firms (see, for example, Hosono and Sakuragawa (2003)). However, there is no a priori reason to assume that there is no unnatural selection in the case of small firms. In fact, a number of practitioners and researchers have argued that the misallocation and mispricing of bank loans is much more serious to small firms. Moreover, given that large parent firms and their subsidiaries are closely related in terms of their activities, it is possible that unnatural selection in the large-firm sector has an adverse impact on small firms. Based on this line of reasoning, the remainder of this subsection examines whether there is any evidence of unnatural selection among small and medium-sized firms.

Natural selection implies that low-performing firms should face higher borrowing costs and are eventually forced to exit the market. Therefore, whether selection is natural or unnatural depends on the sign of the first term on the right-hand side of equation (2). Specifically, we can say that selection is unnatural if

$$
\theta(t, \tau)\left[E_{i \in S(t, \tau)} R_{i}(t, \tau)-E_{i \in D(t, \tau)} R_{i}(t, \tau)\right]>0
$$

and natural otherwise. Similarly, we can say that selection is unnatural if

$$
\theta(t, \tau)\left[E_{i \in S(t, \tau)} Q_{i}(t, \tau)-E_{i \in D(t, \tau)} Q_{i}(t, \tau)\right]<0,
$$

where $Q$ is a variable representing firms' performance (a higher $Q$ means a better performance), which is the operating profit.

Table 4 presents the results of a one-tailed t-test against the null hypothesis that equation (3) holds. Similarly, Table 5 presents the results against the null hypothesis that equation (4) holds. These tables show that we can reject the null hypotheses not only for the entire sample but also for almost all subsamples. For the entire sample, defaulters' borrowing costs are 60 basis points higher than those of

\footnotetext{
${ }^{16}$ An exception is Nishimura, Nakajima, and Kiyota (2005), who use a data set containing small firms. However, the "Basic Survey of Japanese Business Structure and Activities," from which their data are taken, includes no information on default events, so that one cannot identify defaulters and non-defaulters in a reliable way.
} 
survivors, while their operating profits are 2.3 percent lower. One of the few exceptions is the real estate industry, for which we cannot reject the null hypothesis for borrowing costs, although we can safely reject it for operating profits.

To examine the relationship between selection in terms of borrowing cost and that in terms of the performance variable, Figure 6 measures the contribution of selection for borrowing cost on the horizontal axis and that for the performance variable on the vertical axis. As can be clearly seen, there is a negative correlation between the two, which indicates that the lower the quality of a defaulting firm, the higher the interest rate it is required to pay. In this sense, we fail to find clear evidence of mispricing in credit markets.

\subsection{Age versus Size in Adaptation}

We now turn to the analysis of the role of firms' age in adaptation. Figure 7 shows the age profile of firms in terms of their borrowing costs for surviving firms. Specifically, we regress

$$
E_{i \in A(t+1, \tau)} R_{i}(t+1, \tau)-E_{i \in S(t, \tau)} R_{i}(t, \tau),
$$

on age dummies to obtain the slopes of the age profile at different ages. Note that the age profile is depicted under the normalization that the value corresponding to age 0 equals zero, as in Figure 2. If we compare the above expression with equation (1) in section 3.1, we can see that $A(t, \tau)$ is now replaced by $S(t, \tau)$, so that the age profile depicted in Figure 7 represents the contribution of adaptation. We can also see from Figure 7 that the age profile is downward sloping and convex, as in Figure 2. Moreover, the difference of borrowing costs between age 0 and age 50 is now 110 basis points, while it was 170 basis points in Figure 2, indicating that 60 basis points are attributable to selection.

Why do survivors' borrowing costs decline with age? There are several hypotheses to explain this. Diamond (1989) proposes the following. Suppose that lenders cannot directly observe the true quality of each borrower, but can observe each borrower's track record of repayment or default for all past 
periods. Under these circumstances, lenders price their loans based on each borrower's history of default. Specifically, borrowers with a good track record are likely to be firms that have access only to safe projects. On the other hand, borrowers that have experienced default are likely to have access only to risky projects. Based on this Bayesian inference, lenders offer low interest rates to the former borrowers and require high interest rates of the latter. The core of Diamond's hypothesis lies in borrowers' reaction to this pricing policy. Firms that only have access to risky projects have no alternative but to choose risky projects, so they do not change their behavior. However, firms with access to both of safe and risky projects have a stronger incentive to choose safe projects rather than risky ones, simply because they correctly recognize that they can enjoy the benefits of low interest rates in the present and future periods simply by avoiding a default. Importantly, the longer a firm's history of no default, the stronger is its incentive to choose safe projects. This implies firms become more and more risk averse as they age, and consequently they are required to pay lower and lower interest rates. This is Diamond's reputation story.

In the reputation story, each firm's track record of repayment or default plays an important role as a "state variable": firms change their choice among projects as they age simply because the state variable evolves over time. However, firms' credit history is not the only state variable we can think of. In fact, the literature on firm dynamics highlights the role of firm size as a state variable. ${ }^{17}$ Hopenhayn (1992), for instance, introduces persistent productivity shocks in his model and finds that size is the only source of heterogeneity, that is, firms of the same size follow the same dynamics independent of their age. Cooley and Quadrini (2001) introduce a model with financial frictions and i.i.d. productivity shocks, and conclude that firms' characteristics, such as default probability, are dependent on size but are independent of age once size is controlled for. According to their model, a marginal increase in firm size as measured by net worth, leads to an increase in the volatility of profits, which has a negative impact on the firm's value because of financial frictions. On the other hand, due to diminishing

\footnotetext{
${ }^{17}$ For example, Evans (1987a) and Hall (1987) provide empirical evidence that firms' growth rate and the volatility of growth are negatively correlated with firm size.
} 
returns, as the firm's size increases, the marginal expected profits from further increases in size decrease. Consequently, the firm becomes more concerned about the volatility of profits as it grows to a larger size, and borrows less relative to its equity. This leads to a decline in the probability of default and, presumably, to a decline in borrowing costs. Given that firm size is positively correlated with firm age, such a correlation between firm size and borrowing costs implies a negative association between firm age and borrowing costs. However, this spurious correlation between borrowing costs and age disappears once size is controlled for.

Thus the question arises: which of the two factors, firm age or firm size, plays a more important role as a state variable? Is the observed correlation between firm age and borrowing costs merely spurious, reflecting the relationship between the true state variable, i.e., firm size, and borrowing costs? To address this issue, we obtain the age profile of firms in terms of their borrowing costs conditional on firm size. First, we plot how firm size evolves over a firm's life cycle, which is shown in Figure 8. We employ natural $\log$ values of total assets and net worth outstanding as proxies for firm size of survivors and find that both of the variables increase with firms' age. ${ }^{18}$

Next, we regress

$$
E_{i \in A(t+1, \tau, s i z e)} R_{i}(t+1, \tau, \text { size })-E_{i \in S(t, \tau, s i z e)} R_{i}(t, \tau, \text { size })
$$

on age and size dummies to obtain the slopes of the age profile. For the size dummies, we divide the entire sample into four categories either in terms of total assets or net worth outstanding. The results are shown in Figure 9. Note that the lines in the figure are all drawn using the normalization that the value corresponding to age 0 equals zero, so that the slope of each line is the only meaningful information one can read from the figure. The figure shows that the age profiles conditional on firm size are all downward sloping. More importantly, their slopes, measured by the difference in borrowing costs between age 0 and age 50, are steeper when size is controlled for. If the downward sloping age profile is entirely generated

\footnotetext{
${ }^{18}$ Before taking logs, all observations of net worth are normalized to become non- negative by adding the absolute value of the minimum observation.
} 
by the causality via firm size (i.e., firm age $\rightarrow$ firm size $\rightarrow$ borrowing cost), a significantly smaller slope should be observed when firm size is controlled for. However, as far as Figure 9 is concerned, we observe obviously downward-sloping age profiles in terms of the steepness of the slopes, implying that one cannot reject the null hypothesis that firm age is an independent determinant of borrowing costs.

Note, however, that Diamond's reputation story is not the only explanation that would be consistent with our finding. Another possible explanation is provided by the literature on relationship banking. Studies in this field suggest that bank-borrower relationships lubricate the value-enhancing exchange of information (in particular, private information revealing borrowers' true quality), and that the longer the duration of the relationship, the greater the information exchange (see, for example, Petersen and Rajan (1994) and Boot and Thakor (1995)). Empirical evidence supporting this argument is provided by Berger and Udell (1995), among others. Importantly, given that the duration of firms' relationship with a creditor is closely related with their age, this argument could explain the downward-sloping age profile. An important difference from the reputation story is that surviving firms do not change their behavior as they age. Instead, lenders change their pricing behavior over time as they learn about the true quality of their customers. Another possible explanation is provided by Cooley and Quadrini (2001) and has been dubbed the "firm dynamics hypothesis." This hypothesis suggests that size is not the only dimension of heterogeneity but that a combination of financial frictions and persistent productivity shocks has independent age effects on firms' characteristics.

Unfortunately, it is difficult to test the three different hypotheses addressed here - the reputation, the relationship banking, and the firm dynamics hypothesis - against each other, partly because they are not necessarily mutually exclusive and partly because necessary data are not available. However, indirect evidence exists that suggests that the reputation story provides the most likely explanation. Figure 10 documents the development of firms' profitability among survivors, that is, how the adaptation channel functions in terms of firms' quality. This age profile of firms in terms of their profitability is obviously upward sloping, which suggests the following two things. First, since the profitability measure is based 
on business profits before interest payments are subtracted, we interpret the increase in profitability with firm age as the result of behavioral changes by surviving firms themselves rather than by financial institutions. This contrasts with the relationship banking hypothesis, in which not firms but lenders change their behavior, that is, their pricing policy. Second, our empirical finding that younger firms are less profitable than older ones seems to contradict one of the crucial assumptions of the firm dynamics hypothesis, namely, that new entrants are more productive than incumbents. Once the assumption on entrants' productivity is violated, this theoretical prediction points to a positive age profile of borrowing costs rather than a negative one, which again is in contradiction with our empirical findings. In sum, the increasing profitability with firm age (for surviving firms) is more likely to be in conflict with the relationship banking and firm dynamics hypotheses than with the reputation hypothesis.

\section{Conclusion}

This study examined three empirical questions regarding the relationship between firm age and the evolution of firms' borrowing costs, using a unique panel data set of more than 200,000 small Japanese firms for the period 1997-2002. The first question we addressed was whether selection plays a dominant role in the evolution of borrowing costs. The literature on firm dynamics has emphasized the role of selection in the evolution of firm size, and we were interested in whether selection also plays a role in the evolution of financial variables such as borrowing costs. We found that selection can explain about one-third of the total evolution of borrowing costs, indicating that selection plays an important, but not dominant role in the evolution of borrowing costs. The remaining two-thirds are explained by the decline in the borrowing costs of surviving firms as they age. This finding is in line with results of recent empirical studies on firm dynamics, such as Cabral and Mata (2003) and Okazaki (2004).

The second question we addressed was whether the selection we found was natural or unnatural. It has been suggested that one important reason for Japan's prolonged economic stagnation is that zombie 
firms were allowed to stay in the market because of the perverse incentives provided by struggling banks and that the presence of such zombie firms crowded out new entrants with profitable investment opportunities. To examine whether this argument is supported by our data, we looked at differences between prospective defaulters and survivors in terms of their borrowing costs and profits focusing on six industries. We found that defaulters tended to perform worse and pay higher interest rates than survivors, with the exception of the real estate industry where defaulting firms paid lower borrowing costs than survivors. Thus, we find no evidence of unnatural selection, at least among small firms, which contrasts with Peek and Rosengren's (2005) results for large, publicly traded firms. Considering the fact that the majority of bank loans by Japanese banks are allocated to small and medium enterprises, the relevance of natural selection among small businesses should be more pronounced.

The third question we considered concerns the mechanism through which surviving firms' borrowing costs decline as they age. We examined the possibility that this age dependence is the result of a causal chain via firm size (i.e., firm age $\rightarrow$ firm size $\rightarrow$ borrowing costs), but found a similar regularity even when we controlled for firm size. While a number of other potential explanations have been suggested, such as the role of relationship banking and firm dynamics, Diamond's reputation hypothesis continues to provide the most plausible explanation. 


\section{References}

[1] Ahearne, Alan G., and Naoki Shinada. (2005). "Zombie Firms and Economic Stagnation in Japan." International Economics and Economic Policy 2 (4), 363-381.

[2] Albuquerque, Rui, and Hugo A. Hopenhayn. (2004). "Optimal Lending Contracts and Firm Dynamics." Review of Economic Studies 71 (2), 285-315.

[3] Alchian, Armen A. (1950). "Uncertainty, Evolution, and Economic Theory." Journal of Political Economy 58 (3), 211-221.

[4] Baldwin, John R., and Mohammed Rafiquzzaman. (1995). "Selection versus evolutionary adaptation: Learning and post-entry performance." International Journal of Industrial Organization 13 (4), 501-522.

[5] Berger, Allen N., Gregory F. Udell. (1995). "Relationship lending and lines of credit in small firm finance." Journal of Business 68 (3), 351-381.

[6] Bergoeing, Raphael, Patrick J. Kehoe, Timothy J. Kehoe and Raimundo Soto. (2002). "PolicyDriven Productivity in Chile and Mexico in the 1980's and 1990's." American Economic Review 92 (2), 16-21.

[7] Boot, Arnoud W. A., and Anjan V. Thakor. (1995). "Moral hazard and secured lending in an infinitely repeated credit market game." International Economic Review 35 (4), 899-920.

[8] Brown, Charles, and James L. Medoff. (2003). "Firm Age and Wages." Journal of Labor Economics $21(3), 677-697$.

[9] Caballero, Ricardo J., Takeo Hoshi and Anil Kashyap. (2006). "Zombie Lending and Depressed Restructuring in Japan." NBER Working Paper No. 12129.

[10] Cabinet Office of Japan. (2003). Annual Report on Japanese Economy and Public Finance, (In Japanese), Tokyo: Printing Bureau, Ministry of Finance. 
[11] Cabral, Luis M. B., and Jose Mata. (2003). "On the evolution of the firm size distribution." American Economic Review 93 (4), 1075-90.

[12] Clementi, Gian Luca, and Hugo A. Hopenhayn. (2006). "A Theory of Financing Constraints and Firm Dynamics." The Quarterly Journal of Economics 121 (1), 229-265.

[13] Cooley, Thomas F., and Vincenzo Quadrini. (2001). "Financial Markets and Firm Dynamics." American Economic Review 91 (5), 1286-1310.

[14] Davis, Steven J., John C. Haltiwanger, and Scott Schuh. (1996). Job Creation and Destruction. Cambridge, MA: MIT Press.

[15] Deaton, Angus. (1997). The Analysis of Household Surveys: A Microeconometric Approach to Development Policy, The Johns Hopkins University Press: Baltimore.

[16] Diamond, Douglas W. (1989). "Reputation acquisition in debt markets." Journal of Political Economy $97(4), 828-862$.

[17] Dunn, Timothy, Mark J. Roberts and Larry Samuelson. (1989). "The Growth and Failure of U.S. Manufacturing Plants." Quarterly Journal of Economics 104 (4), 671-698.

[18] Evans, David S. (1987a). "Tests of Alternative Theories of Firm Growth." Journal of Political Economy 95 (4), 657-674.

[19] Evans, David S. (1987b). "The Relationship Between Firm Growth, Size, and Age: Estimates for 100 Manufacturing Industries.” Journal of Industrial Economics 35 (4), 567-581.

[20] Hall, Bronwyn H. (1987). "The Relationship between Firm Size and Firm Growth in the U.S. Manufacturing Sector.” Journal of Industrial Economics 35 (4), 583-606.

[21] Hopenhayn, Hugo A. (1992). "Entry, Exit, and Firm Dynamics in Long Run Equilibrium." Econometrica $60(5), 1127-50$.

[22] Hosono, Kaoru and Masaya Sakuragawa. (2003). "Soft Budget Problems in the Japanese Credit Market." Nagoya City University Discussion Paper in Economics No. 345. 
[23] Jovanovic, Boyan. (1982). "Selection and the evolution of industry." Econometrica 50 (3), 649-670.

[24] McKenzie, David J. (2006). "Disentangling Age, Cohort and Time Effects in the Additive Model." Oxford Bulletin of Economics and Statistics 68 (4), 473-495.

[25] Nishimura, Kiyohiko, Takanobu Nakajima, and Kozo Kiyota. (2005). "Does the Natural Selection Mechanism Still Work in Severe Recessions? Examination of the Japanese Economy in the 1990s." Journal of Economic Behavior and Organization 58 (1), 53-78.

[26] Okazaki, Tetsuji. (2004). "Selection and Imitation in Institutional Evolution: Analysis of Institutional Change in Japan, 1960-1999." CIRJE Discussion Papers, CIRJE-F-256.

[27] Peek, Joe. (2004). "The Japanese Banking Crisis: It's Not Over Until the Fat Lady Sings." Presented at the ESRI International Workshop, Tokyo, September 3, 2004.

[28] Peek, Joe and Eric S. Rosengren. (2005). "Unnatural Selection: Perverse Incentives and the Misallocation of Credit in Japan." American Economic Review 95 (4), 1144-1166.

[29] Petersen, Mitchell A. and Raghuram Rajan. (1994). "The Benefits of Lending Relationships: Evidence from Small Business Data." Journal of Finance 49 (1), 3-37.

[30] Petersen, Mitchell A. and Raghuram Rajan. (1995). "The effect of credit market competition on lending relationships." Quarterly Journal of Economics 110 (2), 407-443.

[31] Sekine, Toshitaka, Keiichiro Kobayashi, and Yumi Saita. (2003). "Forbearance Lending: The Case of Japanese Firms." Monetary and Economic Studies 21 (2), 69-91. 
Table 1: Number of Observations

\begin{tabular}{ccccc}
\hline Year & $\begin{array}{c}\text { All } \\
\text { Firms }\end{array}$ & $\begin{array}{c}\text { Surviving } \\
\text { Firms }\end{array}$ & $\begin{array}{c}\text { Defaulting } \\
\text { Firms }\end{array}$ & $\begin{array}{c}\text { Default } \\
\text { Ratio (\%) }\end{array}$ \\
\hline 1997 & 240,384 & 232,811 & 7,573 & 3.150 \\
1998 & 232,811 & 224,005 & 8,806 & 3.782 \\
1999 & 224,005 & 215,404 & 8,601 & 3.840 \\
2000 & 215,404 & 208,644 & 6,760 & 3.138 \\
2001 & 208,644 & 203,337 & 5,307 & 2.544 \\
2002 & 203,337 & 203,337 & & \\
& & & & \\
Total & $1,324,585$ & $1,287,538$ & 37,047 & 2.797 \\
\hline
\end{tabular}

Table 2: Summary Statistics

\begin{tabular}{cccc}
\hline & All Firms & Surviving Firms & Defaulting Firms \\
& Mean & Mean & \\
Variables: & Std. Dev. & Std. Dev. & Std. Dev. \\
\hline \multirow{2}{*}{ Borrowing Cost (\%) } & 2.83 & 2.82 & 3.45 \\
& $(1.22)$ & $(1.21)$ & $(1.63)$ \\
Prime Rate (\%) & 2.38 & 2.38 & 2.42 \\
& $(0.59)$ & $(0.59)$ & $(0.54)$ \\
Age & 23.16 & 23.27 & 19.75 \\
& $(13.44)$ & $(13.44)$ & $(12.92)$ \\
Assets (1,000 Yen) & 594,550 & 600,352 & 389,908 \\
& $(1,113,733)$ & $(1,119,771)$ & $(849,531)$ \\
Net Worth (1,000 Yen) & 89,469 & 91,745 & 9,243 \\
Number of Employees & $(220,152)$ & $(222,121)$ & $(105,674)$ \\
& 23.87 & 24.18 & 12.94 \\
Operating Profit (\%) & $(35.27)$ & $(35.54)$ & $(21.40)$ \\
& 0.40 & 0.46 & -1.56 \\
& $(7.72)$ & $(7.65)$ & $(9.81)$ \\
\hline
\end{tabular}




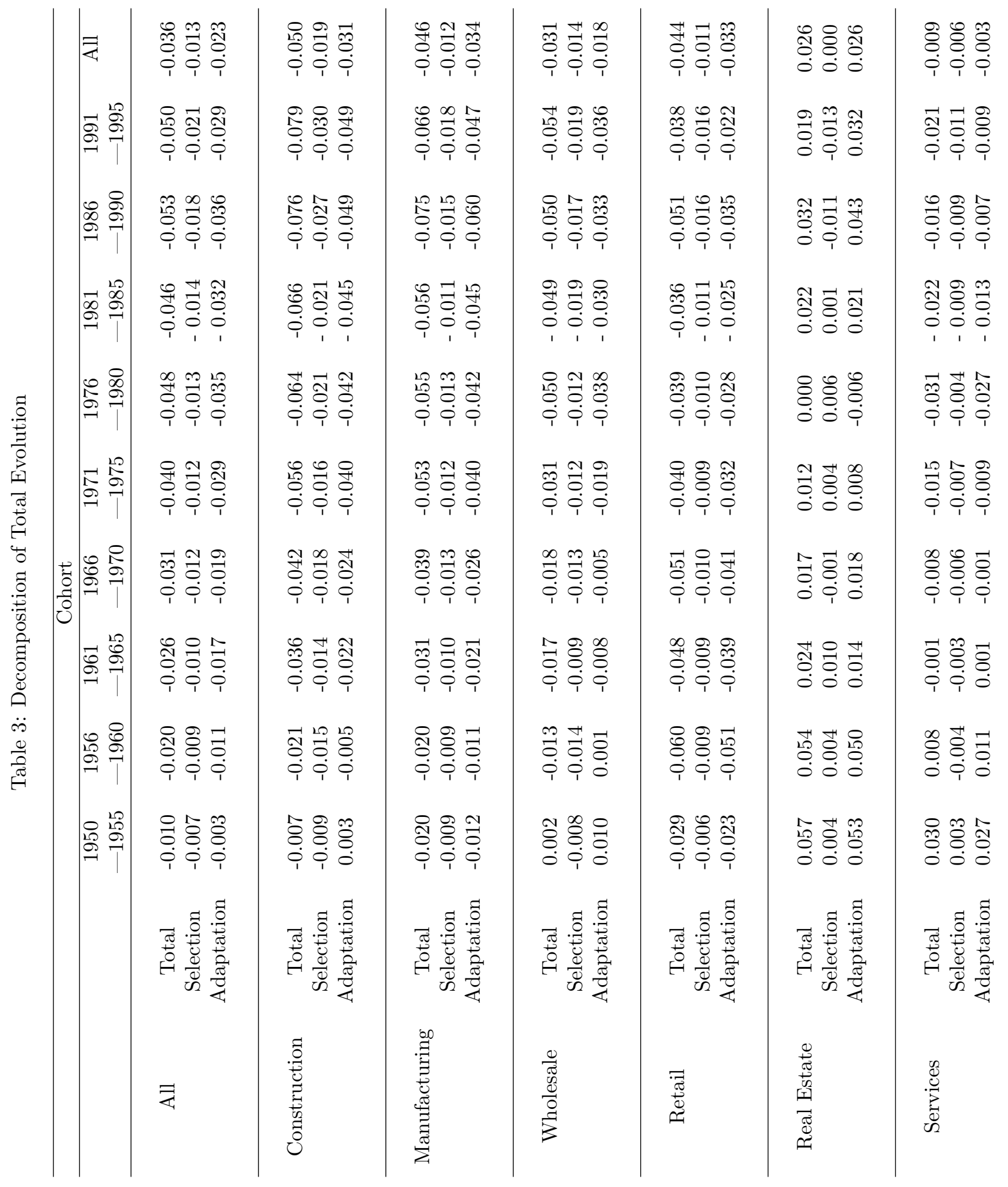




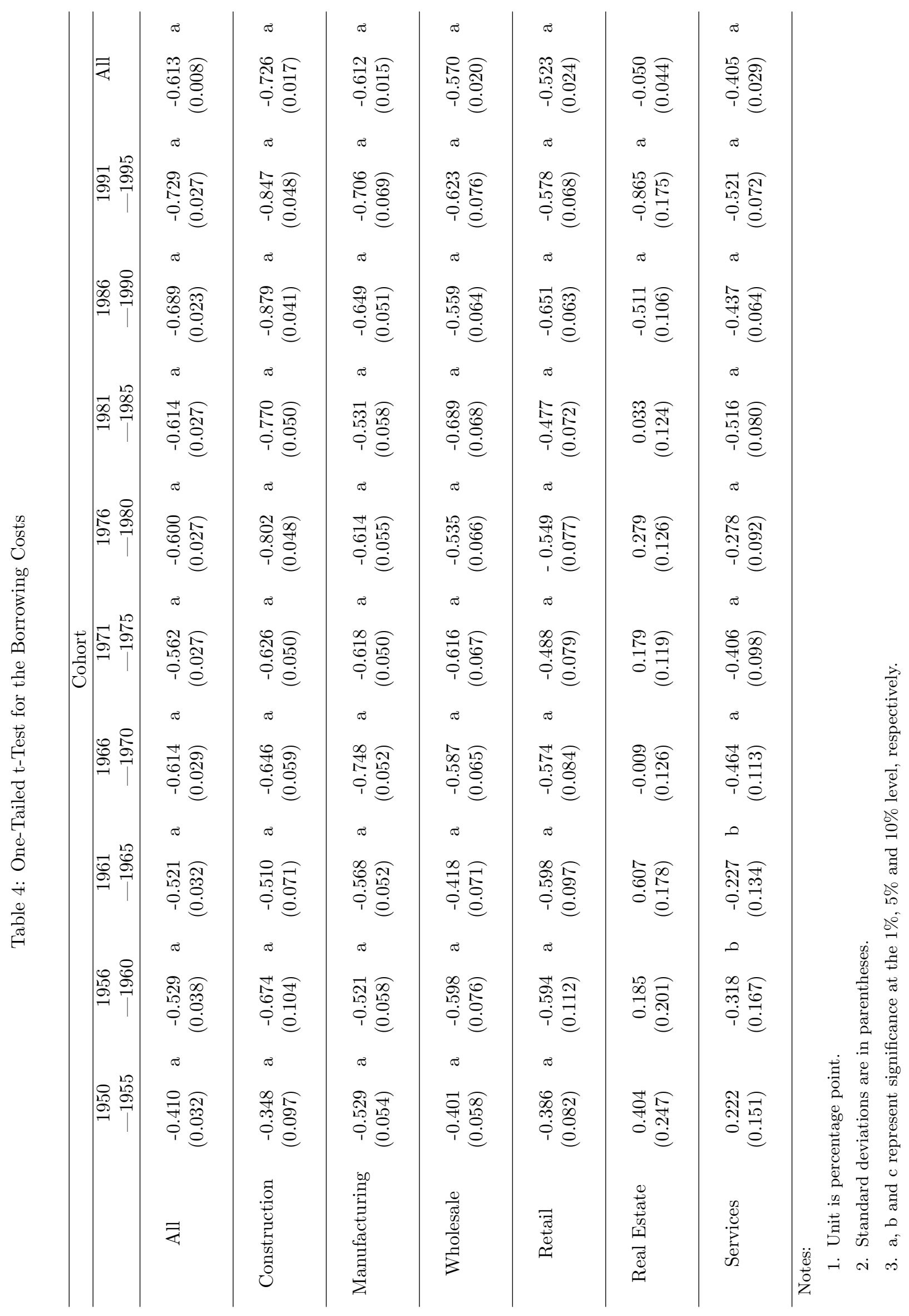




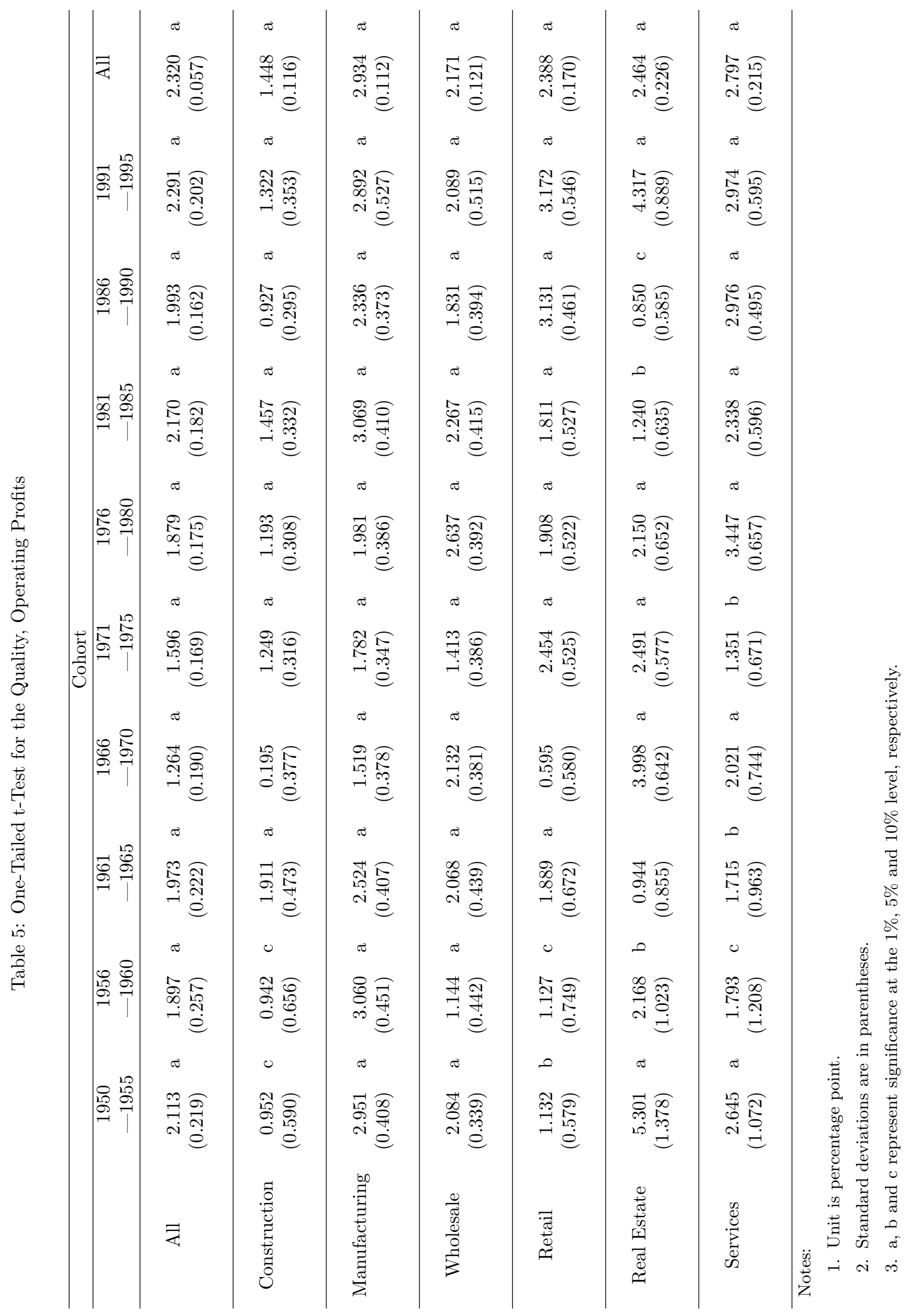




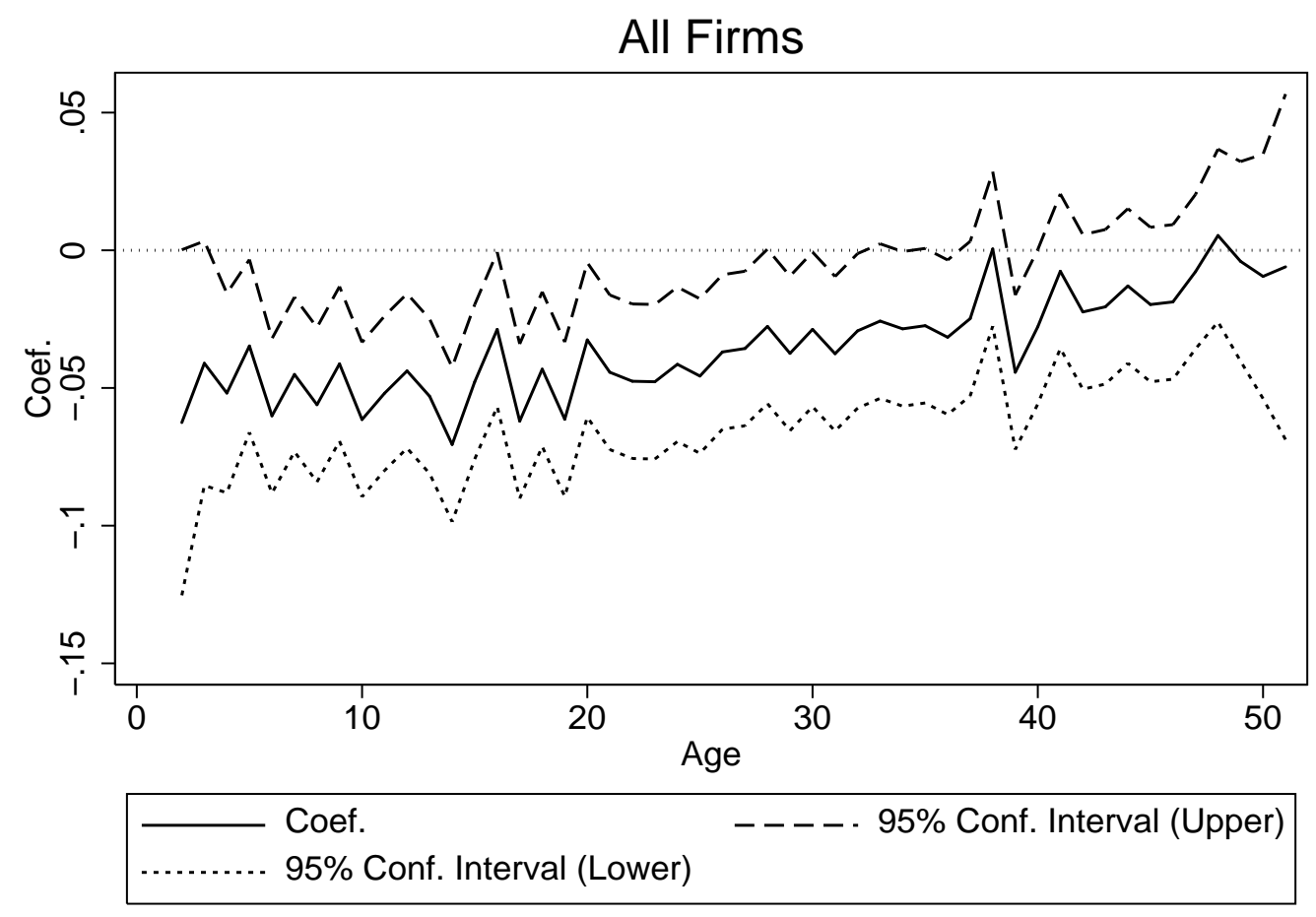

Figure 1: Estimated Coefficients on the Age Profile of Borrowing Costs

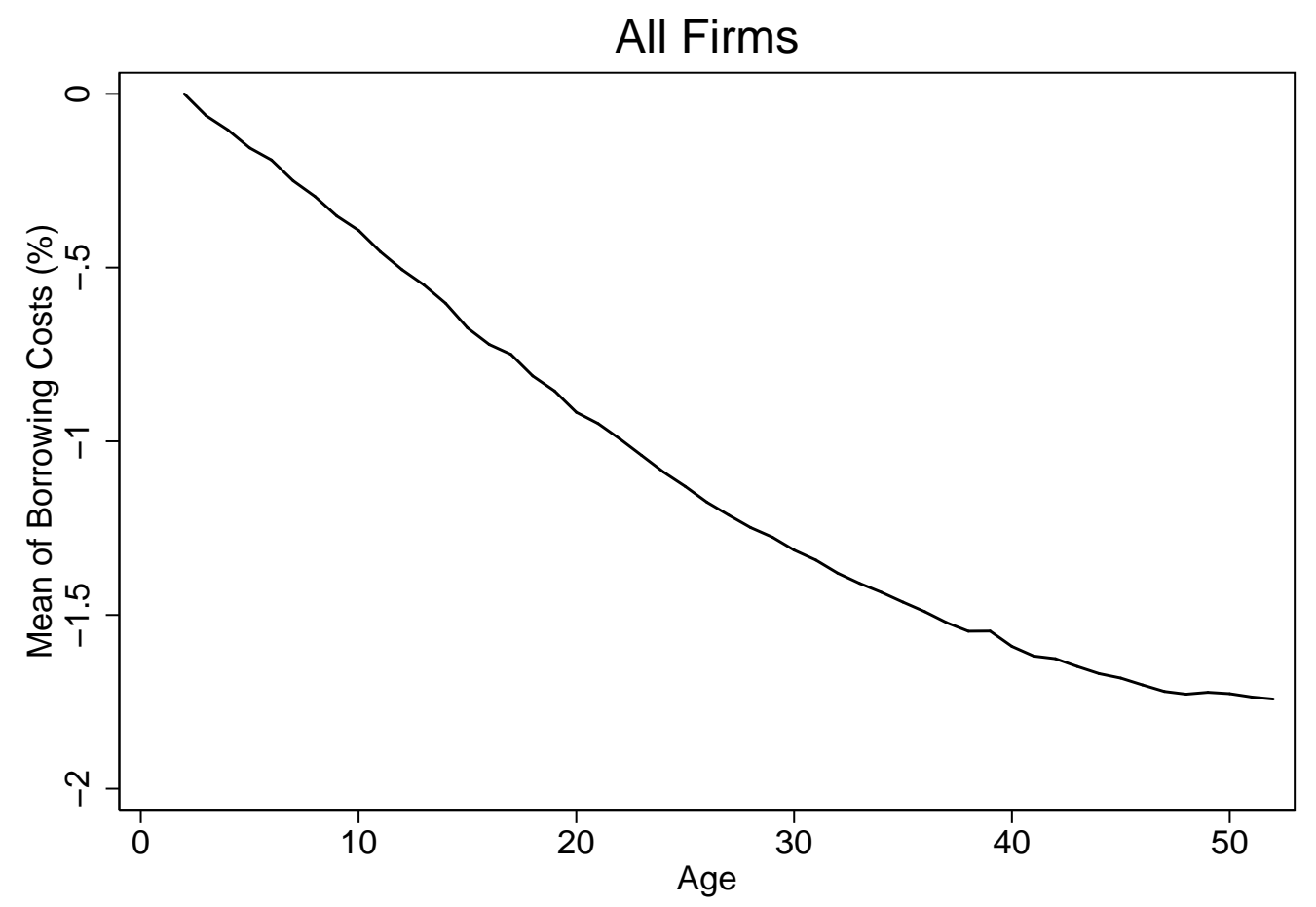

26

Figure 2: Age Profile of Borrowing Costs 


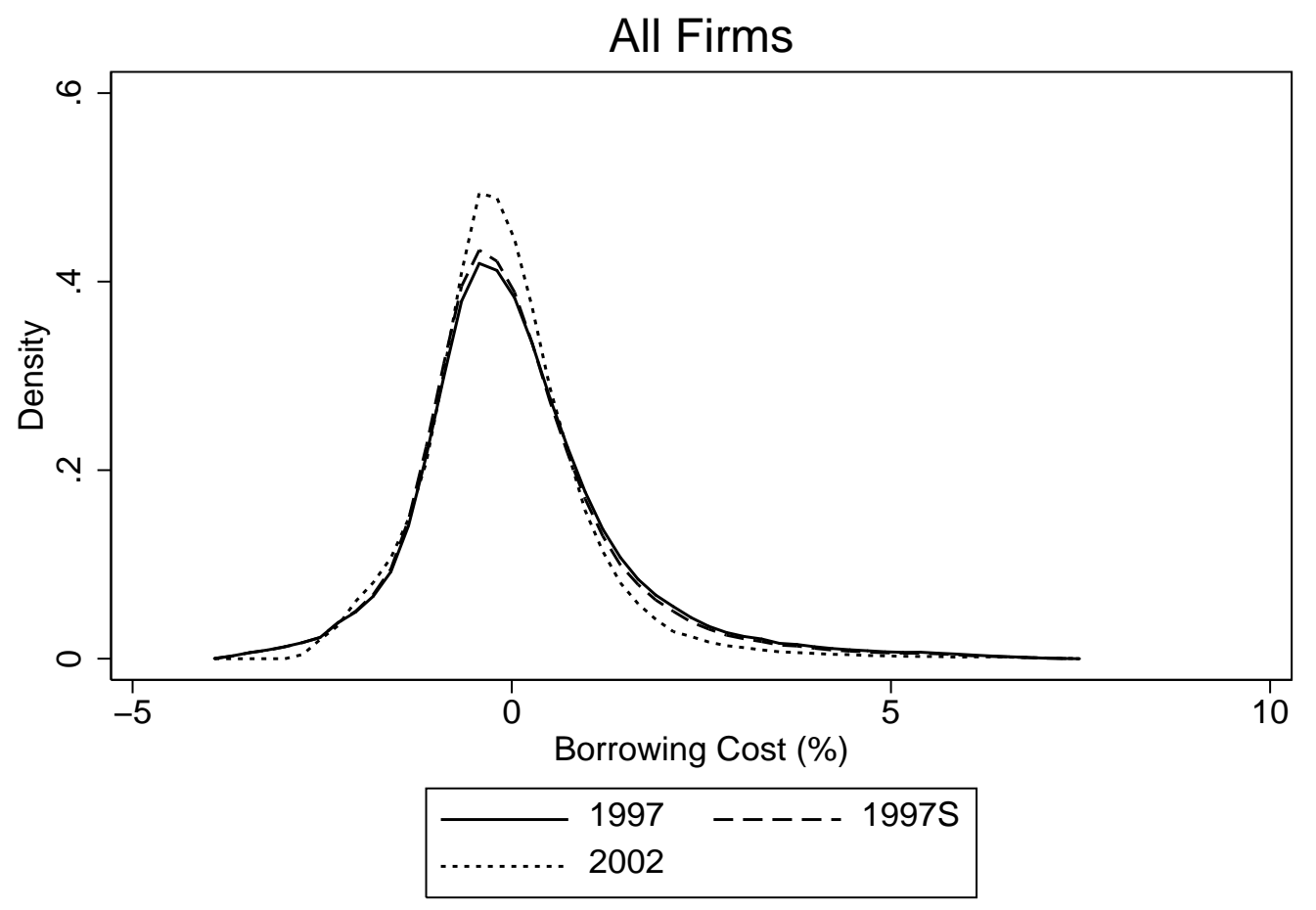

Figure 3: Total Evolution, Selection and Adaptation 

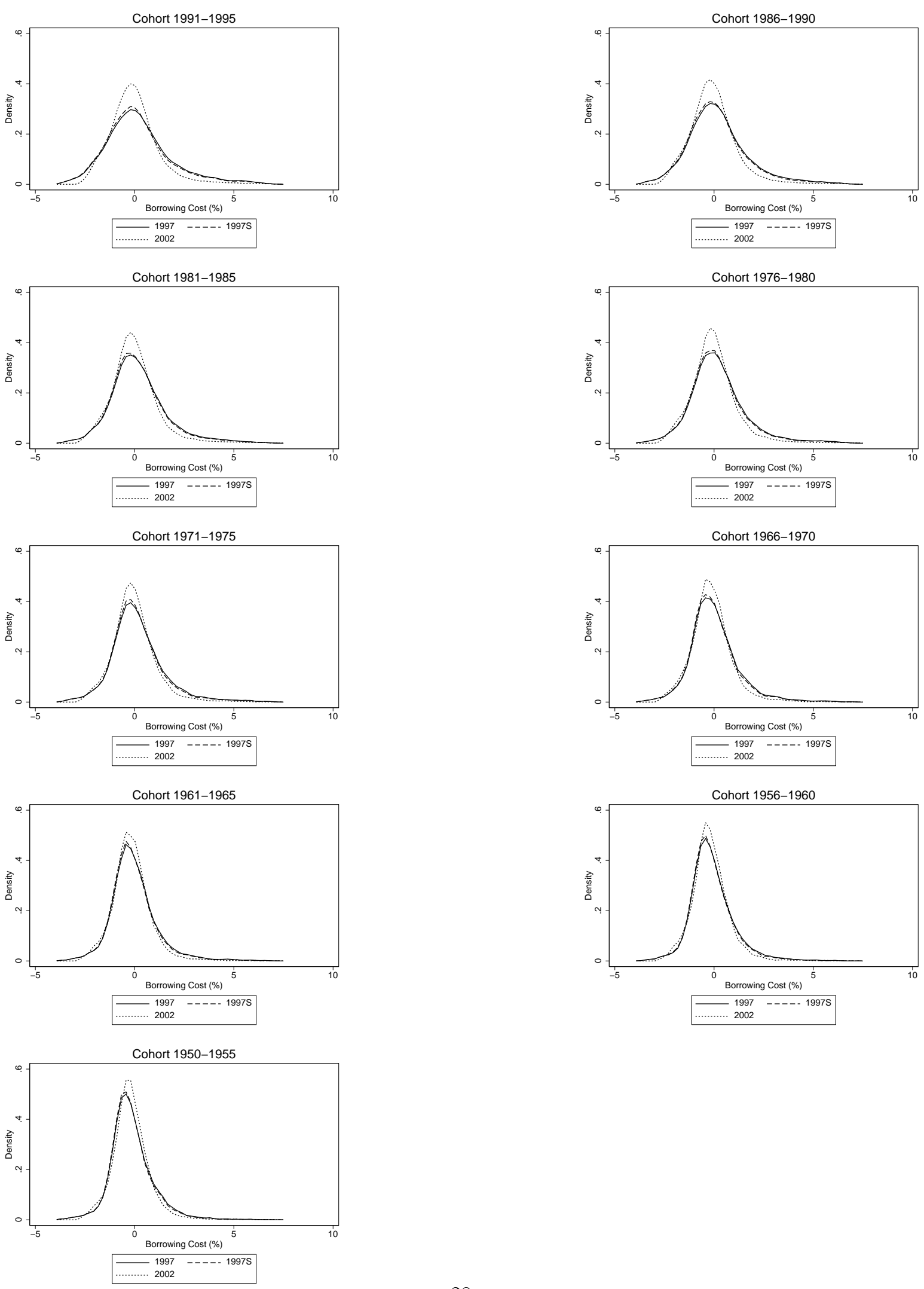

Figure 4: Total Evolution, Selection and Adaptation, by Cohort 


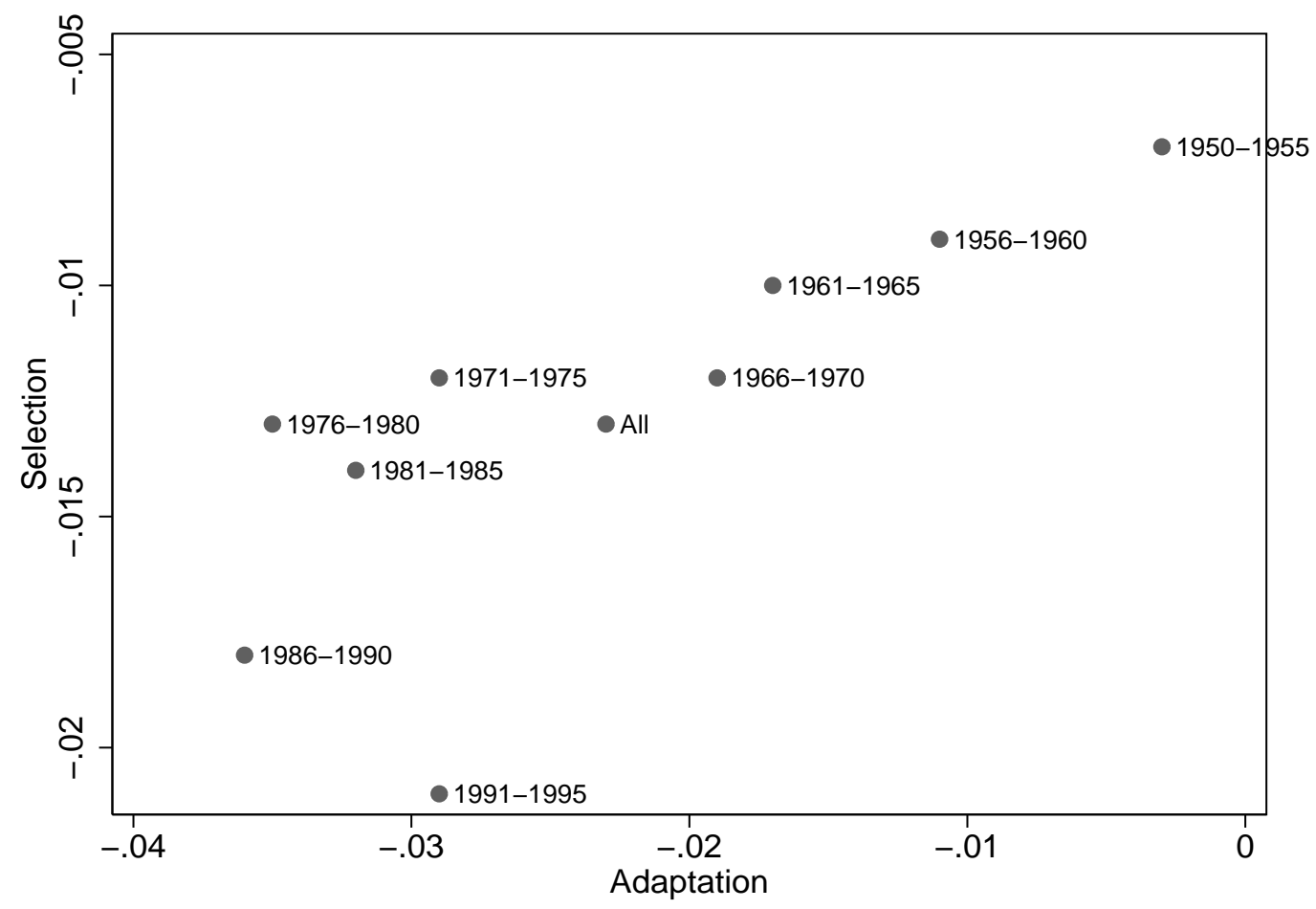

Figure 5: Selection versus Adaptation

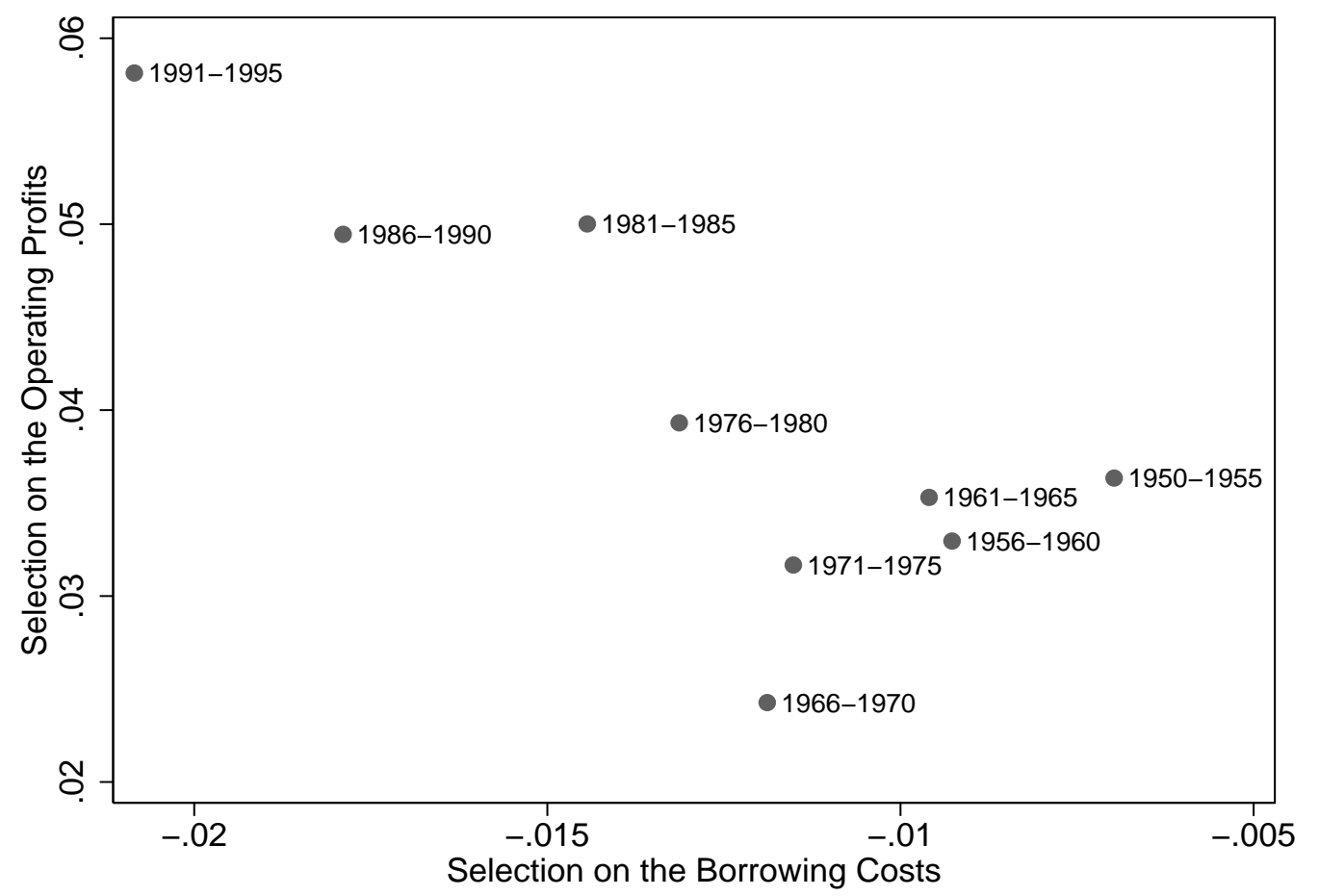

29

Figure 6: Selection on the Quality versus Selection on the Borrowing Costs 


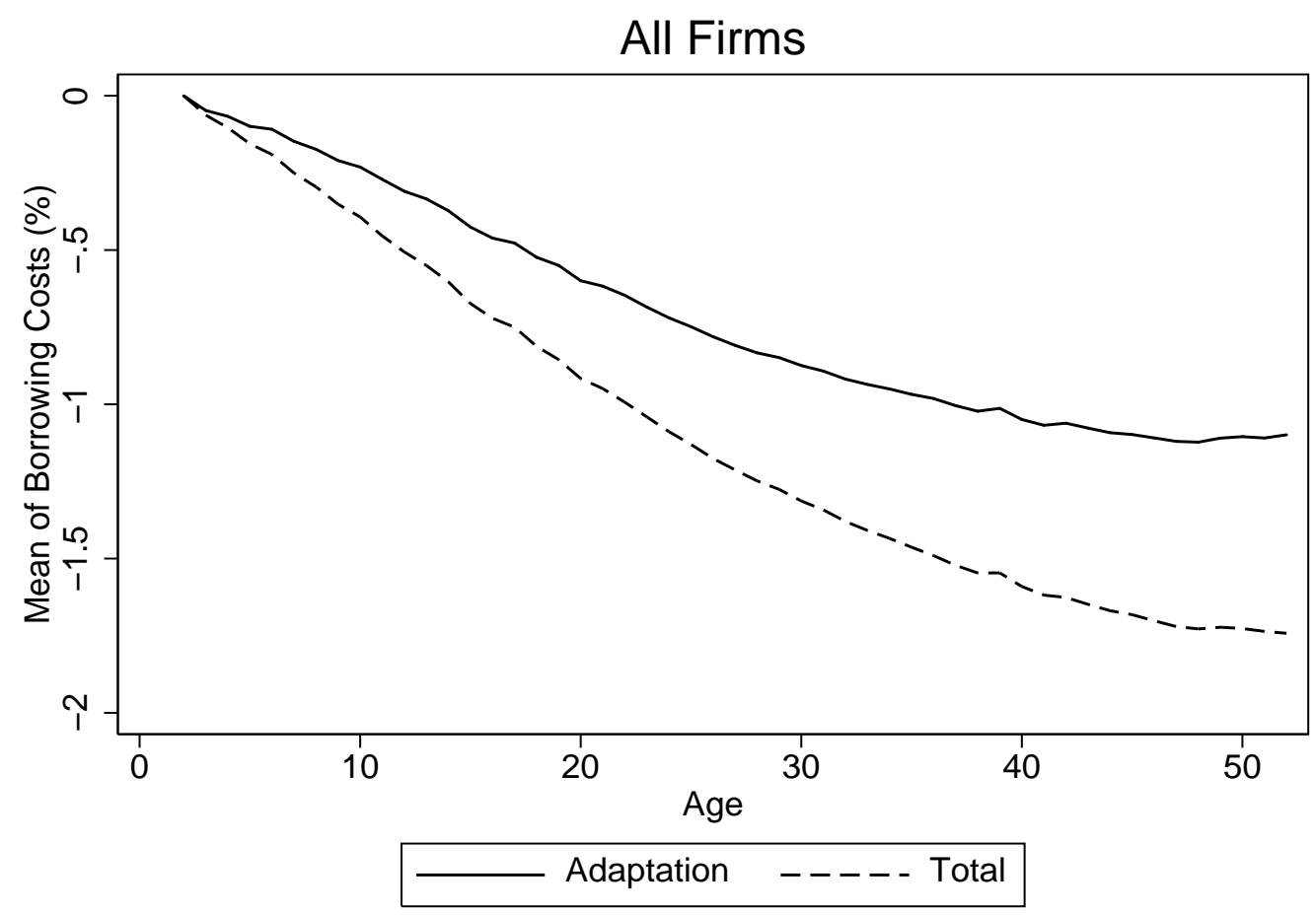

Figure 7: Age Profile of Borrowing Costs: Surviving Firms 

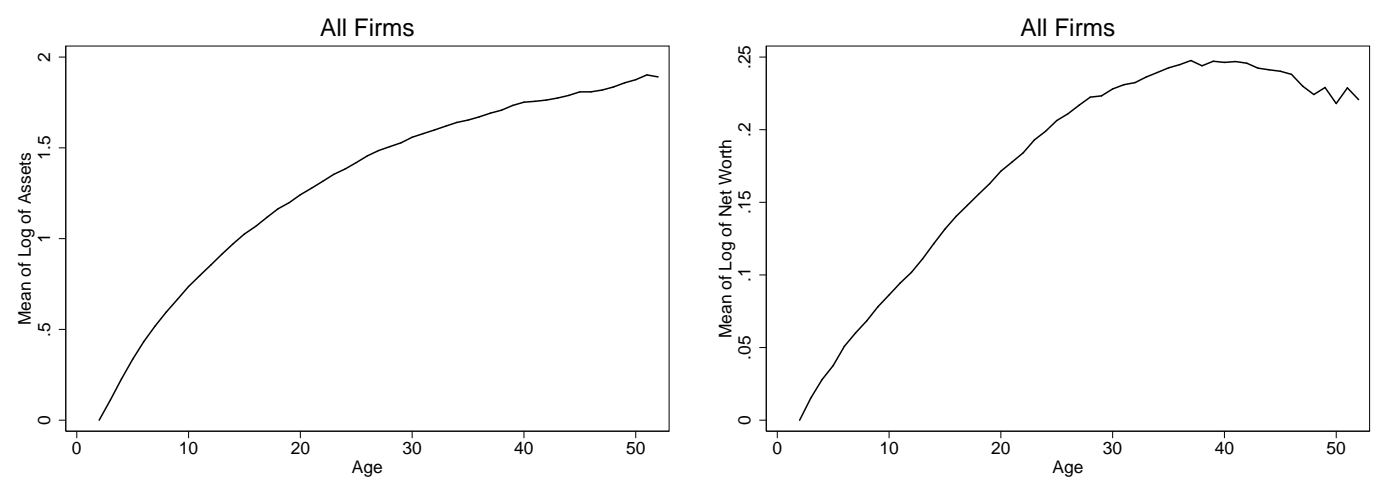

Note:

Figure 8: Evolution of Firm Size: Surviving Firms

1. Size is measured by the log of assets amount outstanding (left) and net worth (right).
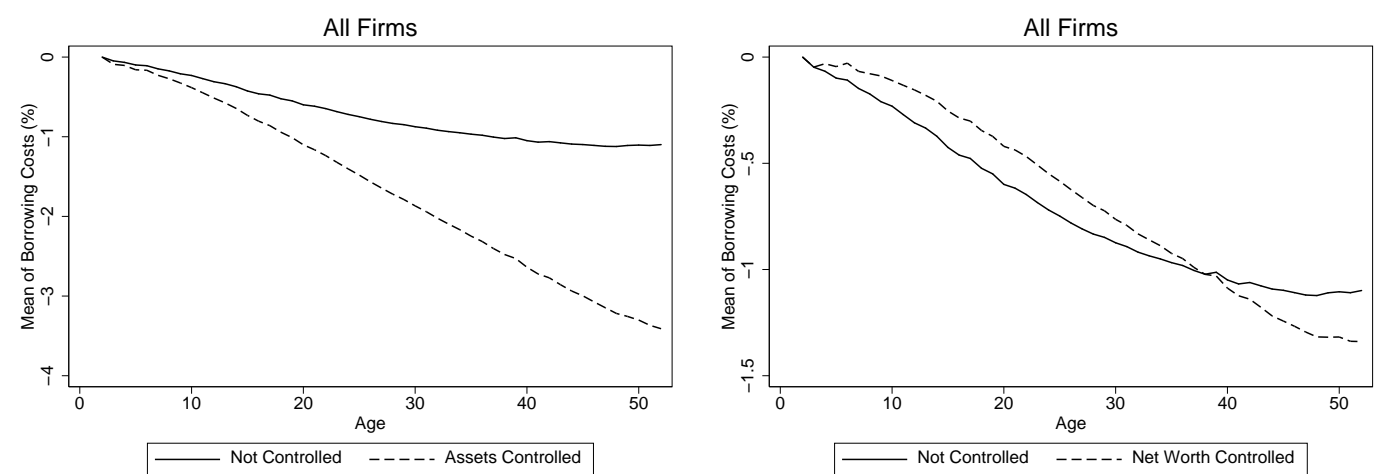

Figure 9: Age Profile of Borrowing Costs Controlled by Size: Surviving Firms

Notes:

1. Dotted lines are the age profile of borrowing costs controlled by size.

2. Size dummies are generated by the assets amount outstanding (left) and net worth (right). 


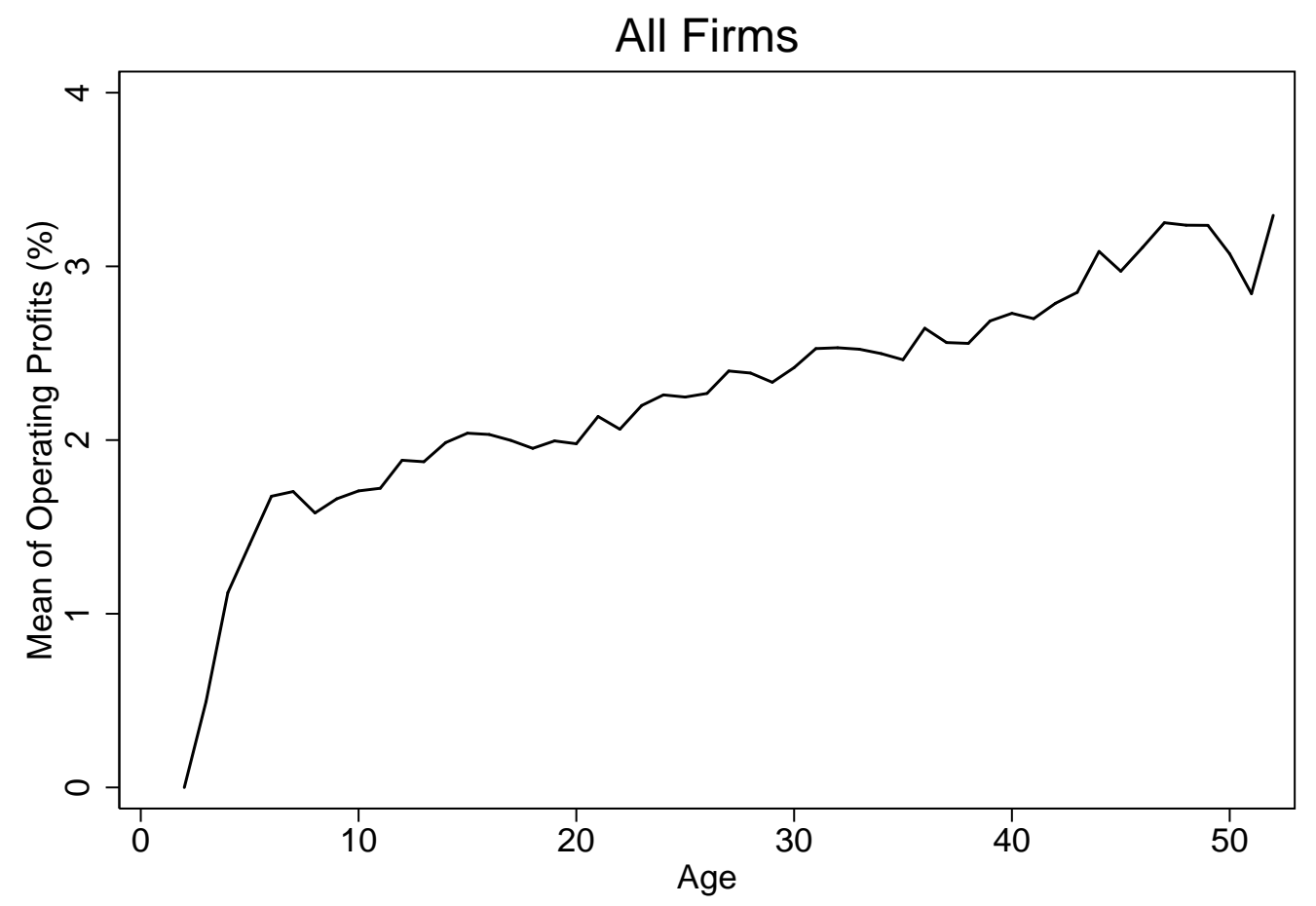

Figure 10: Age Profile of Operating Profits: Surviving Firms 